\title{
Beyond Social Media Determinism: How Artists Reshape the Organization of Social Movements?
}

\author{
Alberto Cossu
}

\section{Introduction}

The main aim of this chapter is to identify the relational mechanics at work within Macao, an artist-led occupied cultural space. To this end, three main dimensions will be explored. The first tackles the connection between the individual and the collective level of participation, a distinctive connection that produces what I define as a nonexclusive dialectic between the two levels. The second investigates the organization of participation through the opposed and coexisting notions of horizontality and hierarchy, analyzing the constantly shifting balance between radical inclusion and leadership. I will stress how this configuration allows for a legitimate monopoly of symbolic capital of recognized leaders that coexists with Macao's refusal of horizontality - one of the supposed axioms of contemporary mobilizations. The third and final dimension is the process of developing a collaboration, which helps to build and maintain relations and handle conflicts in a better way. This last dimension will run more as a background dimension to this chapter, as it is embedded in the first two dimensions and influences Macao's relations in a more encompassing way. These three dimensions constitute a point of departure for the exploration carried out in this article and a point of arrival: they indicate a hybridization of the classical dichotomy between centralism and spontaneity sparked by Michel's theory (Barker, 2001). These dimensions frame this chapter within a growing scholarly debate which aims to stress the limits of horizontality (Nunes, 2014; Roberts, 2012; Western, 2014). What is at stake, then, is the understanding of emerging forms of organizing which exist within the binary opposition. The

\footnotetext{
Protest Technologies and Media Revolutions, 141-159

Copyright (C) 2018 Alberto Cossu. Originally published in Social Media + Society, January-

March 2018: pp.1 -13, SAGE Publications. Republished with permission. Creative Commons

Non Commercial CC BY-NC: This article is distributed under the terms of the Creative Commons

AttributionNonCommercial 4.0 License (http://www.creativecommons.org/licenses/by-nc/4.0/) which permits non-commercial use, reproduction and distribution of the work without further permission provided the original work is attributed as specified on the SAGE and Open Access pages (https://us.sagepub.com/en-us/nam/open-access-at-sage).

doi:10.1108/978-1-83982-646-720201011
} 
porosity of the dimensions presented above reflects an attempt to overcome the limits of such a dichotomic approach and is in line with the aim to pin down Macao's organizational model. By doing so, I intend to show how an inversion of the traditional equation of organizational forms, now become transient configurations determined by the eventfulness of their routine activity, is taking place within this new wave of activism. As I will argue, Macao in fact appears not as a well-defined organization that produces events but rather as a link between events in itself. The event is a central notion to understand Macao's organizational dynamics along with its logic of political mobilization and processes of cultural production. As suggested by Cossu and Murru (2015), the logic of events is a pragmatic concept that focuses on the cultural and symbolic elements over the technological affordances provided by social media to account for the success of political mobilizations. More recently, I could argue how the event represents their minimal economic unit: hundreds of events are organized every year, providing the city an alternative stage for arts and culture (d'Ovidio \& Cossu, 2016). Within this frame, I suggest that the event also acts as an organizational device; Macao does not produce events in order to persist as an organization with its structures and roles but as a series of events that become the organization of action and communication.

\section{The Case Study and Methods}

Macao was created during the winter of 2011-2012 as part of 'Lavoratori dell'Arte' (LdA, Art Workers), a group of artists, art critics, curators, journalists and activists who had been politically active in Milan since the previous autumn. Macao defines itself as the 'New Centre for Arts, Culture and Research of Milan'. In the first phase of its existence, it was an idea in the making, which became visible in April 2012 with a Twitter profile, a YouTube channel and a Tumblr site. Macao became an open space for citizens to experiment with new modalities of art, culture and research only in May 2012, when hundreds of cultural workers occupied an empty skyscraper (Torre Galfa) in the centre of Milan. They were evicted some days after the occupation; a few weeks later, they managed to occupy a former slaughterhouse and moved in there. Macao is part of the Italian Network of Occupied Theatres, active since 2011, and a player in the international artistic activism scene.

Macao can be viewed as many things: a hub, a brand, a space, a process, a group of activists, a venue for concerts, a number of rooms bookable for free for seminars or exhibitions, an alternative innovation centre, a partner for EU-funded projects or an illegal squat. Since its inception, its rank and file has been both highly engaged and diversified at the same time. According to the self-inquiry conducted by Macao on its base in winter 2012, participants in the mobilization were 'working' a staggering 35 hours a week, on top of their day jobs. To provide a snapshot of the activity, the average Macao activist is in his or her mid-30s, highly skilled, usually with a degree and with more than one job and is dissatisfied with both his or her income and job type. 
Several scholars have done research on Macao. Among the existing publications, some focus directly on Macao, while others mention Macao as part the Italian Network of Occupied Theatres. Concerning the first, Chiara Valli's work (2015) originates from a social geography perspective combined with a Foucauldian frame and aims to assess how aesthetics have played a central role in the political subjectification process in Macao. The other contributions, although originating from both academic (Giorgi, 2014) and extraacademic milieus (Cirillo, 2014), contextualize Macao within the broader struggle that the Italian 'Network' has brought forward.

This chapter is based on a two-year period of ethnographic research (December 2012-December 2014) that I conducted for my PhD. It consisted of participant observation, 30 semistructured interviews and digital methods (Rogers, 2013). I was given access as an analyst to Macao's social media channels for my research, while the anonymized data from the mailing lists presented in Section 4 was extracted from my own email account as it was available to anyone inside the mailing list. Email data were then elaborated using the software Gephi. In terms of my position as a social movement (SM) researcher, I have shared the frame of militant research (Mirzoeff, 2013) to the extent that the research was conducted working 'in and with' the movement that was the object of the study.

\section{Framing Organization in Hybrid Movements}

In the last decade, a body of literature on organization studies (OS) and SMs has been emerging, highlighting the fact that a convergence of organization and SM studies may be taking place (Davis \& Zald, 2005). As noted by Clemens (2005), however, SM scholars demonstrate a deep discomfort with the concept of organization. Conceived as a system of order and authority, it seems incapable of taking into account processes of social change. As McAdam and Scott (2005) highlight, the two fields traditionally focused on different domains (e.g., formal institutions in OS, emerging organizations in SM) and prioritized different aspects (structure in OS, process in SM). However, if certain strands of SM theories have progressively accepted the formalization of OS (e.g., resource mobilization theory), new developments in OS in terms of nonrational actor models and cognitive and cultural explanations still have to be integrated into SM theory (Campbell, 2005, p. 42). Furthermore, researchers have argued how recent SM theory has failed to adequately conceptualize strategic leadership in movements. In particular, Ganz (2000) suggests that it is the movement's leader, along with the movement's networks and strategic capacities, that is crucial to success, rather than the resources and political opportunity structure. More recently, growing attention has been dedicated to how activists are able to avoid structures and processes of institutionalization, with new media playing an important role in providing a nonhierarchical environment. This is the case with connective action (Bennett \& Segerberg, 2013), where social mechanisms characterized by weak ties have allegedly made it possible to overcome the rigidity of 
collective action, whereas the latter is conceived of as a superstructural process that endangers freedom and fluidity. An indicator of this trend is the latest work by Manuel Castells, where he conceives of an autonomy of 'third spaces' - the spaces resulting from the interconnection between occupied urban spaces and digital networks - as being based on the intrinsically free nature of the online space (Castells, 2012, p. 222). Other studies highlight, however, how digital networks are deeply influenced by mechanisms of verticality, authority and exclusion (Gonzalez-Bailon \& Wang, 2013; Nunes, 2014). Other authors (Arvidsson, Caliandro, Airoldi, \& Barina, 2015; Gerbaudo, 2015) state that we need to overcome the network paradigm in order to better understand the crowd dynamics that are emerging in social media as well as in processes of mobilization.

SM studies have only recently shown a renewed interest in power and leadership dynamics. In the aftermath of Occupy, 15M and the Arab Spring, they have resurfaced, countering the overwhelming quantity of contributions that have emphasized the flat and distributed nature of the new forms of mobilization. However, following Leach (2013), we can look back and see how in the last 50 years of US mobilizations there have been countless attempts to avoid hierarchy through prefiguration, direct action and other nonhierarchical organization models, invariably resulting in what JO Freeman (1972) famously defined as the 'tyranny of structurelessness'. In a similar vein, Roberts (2012), in discussing why Occupy failed, refers in particular to the limits of horizontalism and the culture supporting this particular organizational and political choice. Within the literature that attempts to return attention to issues of leadership and power, and within the field of SMs, the contribution of Simon Western (2014) helps us to recall how anarchists like Bakunin, Proudhon and Kropotkin did not have particular taboos regarding dealing with leadership. For them 'individuals and groups take temporary leadership autonomously and on behalf of the wider collective, without assuming a formal position of power or authority over others' (Western, 2014, p. 676). In this respect, interesting connections emerge between the issues of leadership, entrepreneurship and processes of political mobilization. Critical management studies have recently brought these three areas together (Swann \& Stoborod, 2014) from an anarchist point of view similarly to what Gregory Sholette (2011) has proposed in the field of art criticism in his latest book, in which he analyses the artistic world and its approach to enterprise culture. From a different angle, SM scholars interrogate the same nexus that brings together cultural innovation, artistic radicalism and forms of disruption to existing capitalist forms. Davis, in particular, focuses on topological similarities among SMs and enterprises (Davis, McAdam, Scott, \& Zald, 2005, p. xiv). What, then, are these movements? Are they still movements as we used to know them, with the same recruitment and organizational mechanics? In the attempt to capture the specificity of movements that embody the heritage of artistic avant-gardes, workers' movements and start-ups, a multiplicity of perspectives must be interwoven. In the Italian and international context, growing attention has been paid to cultural and social entrepreneurship, to social innovation and to peer-to-peer forms of production and organization (Arvidsson \& 
Peitersen, 2013). At the same time, SMs and squatting centres have radically changed (Moore, 2015; Prujit, 2013), increasingly becoming hubs of cultural production and experimentation rather than spaces of social healing and inclusion. In other words, hybrid forms are emerging in this complex field, and Macao is certainly one of them.

\section{The Materiality of Macao's Relations}

Dust, paint, sweat, smell of sweat, detergents, brooms, dustpans, paper, wood beams, coffee, pasta, couscous, coffee, beer, wine, myrtle, cigarettes, computers, music, books, photographs, songs, dances, assemblies, respect, growth, smiles, rages, fears, hugs, kisses, dreams, passions ... encounters.

This excerpt from the diary of Macao was written during the summer of 2012. It allows us to understand the material, emotional and symbolic dimensions that were attached to the making of Macao. In fact, shortly after the occupation of the former slaughterhouse in Milan (June 2012), Macao launched a Summer Camp. This was a two-month long initiative to turn the building into a hospitable place for Macao. The Summer Camp served multiple purposes, and through it, we can see some of the key elements that characterize relations in Macao. In the first place, it satisfied a need to widen and consolidate relations inside the organization.

I wake up rested, perfumed in a soft and cleaned bed ... what a strange feeling! It was a couple of weeks that did not happen ... if I knew this would not happen anymore, I think I'd go crazy. Yet now, in the comfort and cleanliness of my house I feel trapped, I miss my friends' laughter, the endless discussions and that sense of community, where everyone gives, for better or for worse, in stress and in joy. And so on, riding my horse, wind in sails and wings spread to Macao.(Summer Camp day 2)

In this first period, those people in Macao who had technical skills organized the work so that others could learn and be safe when carrying out work which was not always intuitive and immediate or safe. Macao exemplifies a new entanglement of arts with the crafting an alternative organisation. We can interpret this as the latest iteration of an ideal progression that moves from the dematerialization of art, to the relational and social turn, and now becomes a living process that is deeply rooted in everyday practice (Picture 11.1).

The Summer Camp also served the functional imperative of improving the quality of the space and resignifying the space itself, a task that was achieved with a particular aesthetical/political frame in mind. In order to better describe this frame, 


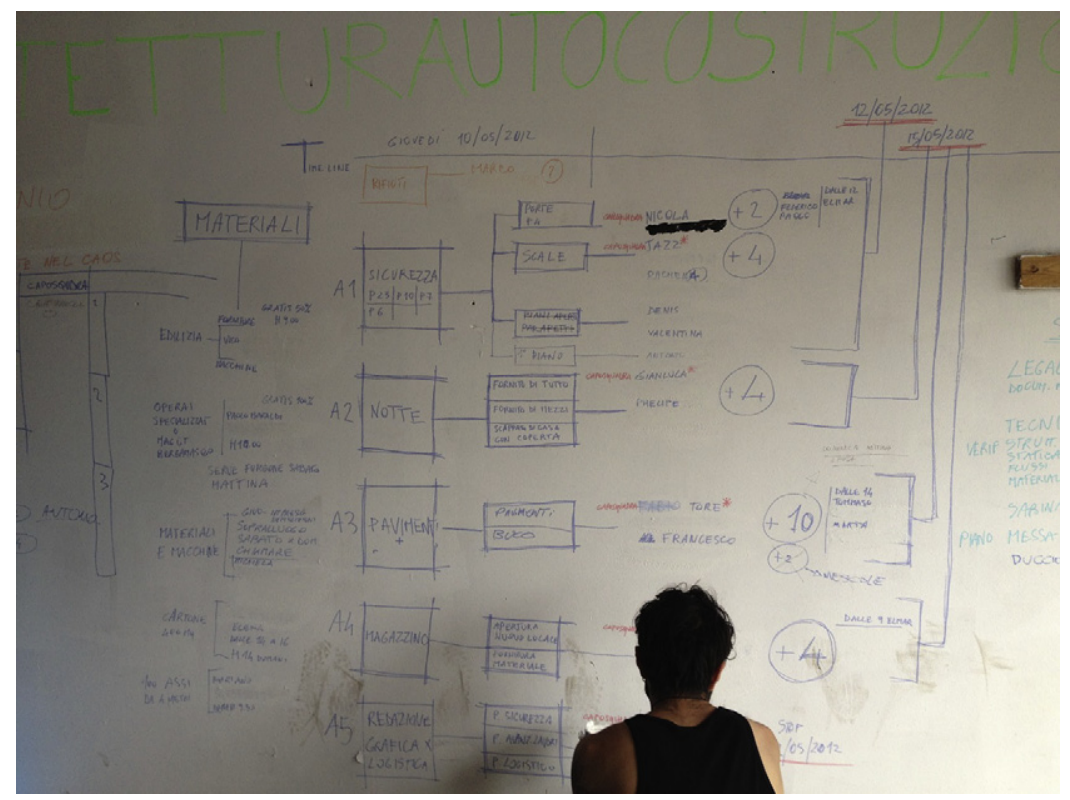

Picture 11.1. Differentiation of Tasks and Organization in Macao.

I combine an ethnographic with an historical analysis, finding substantial analogies with the ideas previously developed by the Isola Art Center - in which some of the Macao founders were involved (and are still involved, in some cases) - in clear opposition to the practices of the institutional art world. In the first place, their idea of having a space as a dirty cube - opposing the idea of the neutral white cube, which is widespread in museums and exhibitions - implies refusing a denaturalizing aestheticisation of the occupied space. In other words, in order to create a New Centre for Arts and Culture that intends to host and produce alternative art and culture, this conception must be perceivable also in aesthetic and architectural terms. This meant leaving the marks of abandonment visible, to apply a selective political/aesthetical judgement according to which it appeared legitimate to reveal the marble - covered in a dull white paint - that framed some of the doors but, at the same time, to avoid the temptation to paint entire rooms anew. Secondly, the notion of fight-specific underlies that the cultural and artistic processes taking place in the occupied space must take into account the local needs. In this sense, resignifying the space implied establishing a dialogue with the neighbourhood, organizing initiatives and explorations of the vast area that surrounds it (for example, walks in the abandoned slaughterhouse), making the walls of the former slaughterhouse's exchange speak and porous to influences from the outside. Third, and finally, the idea of a dispersed centre, that is, conceiving of the art centre not as a physical space but rather as a mental and bodily attitude (cf. Isola Art Centre, 2013). 
Furthermore, the Summer Camp expressed a will to establish an image of Macao as a positive and constructive force for the city of Milan. In this respect, the Summer Camp can be viewed as one of the first projects that was developed in the former slaughterhouse exchange, through which a part of the citizenry of Milan was involved. More precisely, it provided those stuck in the city - cities are deserted in Italy in August due to the traditional Italian summer break - with an alternative way to learn new things, to cooperate, to work and to be part of something. In fact, in a YouTube video created for the launch campaign in April 2012 by the autonomist intellectual and activist Franco Berardi, 'Bifo', clearly states that occupying should not constitute an end in itself and that what has to be done goes far beyond that. In his words:

This is what we have to do, rebuild solidarity, and to do that, Macao: burn banks, set London and Athens aflame, block roads, occupy the factories - of course, if all this is necessary. But maybe what is essential is the word, the sign, the dream, the imagination, in every possible way.

The relevance of Berardi's comment is at least twofold. In the first place, his focus on solidarity is an attempt to stress how only together we can overcome our 'sad times'. This is the same trajectory that was followed and experienced by Macao activists, sick as they were of the depressive self-pity so widespread in the previous assemblies of precarious workers in which they had participated. Secondly, it signals the performative role of the intellectual discourse in the shaping of a movement. It is noteworthy how his contribution appears in line with what will become the concrete activities of Macao: in particular, if we consider how intensely Macao worked on the sign and the image. This 'heritage' highlights the affinities of Macao with the theorists of the previous generation. Furthermore, the very fact that it was possible for Macao to secure the endorsement of influential public intellectuals and artists - similarly not directly engaged in political activity - reveals the peculiar social status of Macao's founders: a kind of marginal élite within the Italian cultural realm, bearers of high cultural capital, with upper and middle class backgrounds, who directly took part, often with highly visible roles, in the previous waves of mobilization both at the national and international level. This is a sort of cobelonging that not only ties Macao activists to leading figures in critical thought but also to more institutional actors in the city of Milan.

\section{Conflicts and Division of Labour in Macao's Experience}

As Macao activists have also experienced, being part of a movement also means dealing with conflicts. It is in the latency phase of a movement that an "everydayness' overcomes the initial euphoria. This also had to do with the changing composition of Macao. In fact, starting from the relatively homogenous group of Macao's 'founders', hundreds of people joined the process in the 'normalised' 
phase, the start of which coincided with the occupation of the former slaughterhouse exchange. After June 2012, video makers, employees, students and others joined Macao.

Particularly relevant conflicts emerged around the issues of gender and material vs knowledge. The starting point here is the understanding that the sheer fact of being together in Macao, both individually and collectively, did not result in differences among participants being overlooked. Therefore, as conflicts arose, assemblies were called to discuss such issues, and in some particularly relevant cases, seminars and meetings were organized in order to cope with them.

Gender, at least in numeric terms, is not an issue for Macao. The overall composition of Macao shows a substantial equity in terms of male and female distribution, as the self-inquiry conducted by Macao makes clear (26 males and 24 females in December 2012). What was at stake, then, were the imbalances in roles and functions within the organization. During my ethnographic study, I was able to grasp how, among the activists, there was a perceived unease regarding a male dominance in the assemblies. In particular, during a seminar organized in March 2013, called 'Occupare il conflitto' ('occupying the conflict'), Macao activists pointed out how males were more likely to take turns talking during the assemblies and to speak for longer, and they were much more likely to occupy the public sphere. However, during this seminar, led by Federica Giardini, a feminist and political philosopher from the University of Rome, the picture was revealed to be far more complex. In particular, it emerged that relations are not determined by gender belonging per se. In fact, as a Macao activist said in his intervention during the seminar:

It has nothing to do with being male or female, it relates to a masculine or feminine attitude. Here in Macao there are female people who have masculine attitudes. They shut me up within the assemblies, and I cannot take the floor (audience laughs) because they have this attitude. Therefore, it is reductive to say that in Macao assemblies, or in the national and public meetings, only men can speak - it is about a masculine attitude.

Furthermore, it is not that women have no voice in Macao: they express it in different ways and using different channels, one of which is social media. Using digital methods and techniques (Rogers, 2013), I have analyzed the flows in the Macao mailing list. The data refer to the main mailing list used by the activists, labelled the 'Communication Mailing List' (CML). This mailing list was initially dedicated to the discussions of the group in charge of Macao's external communications. Later on, this mailing list actually came to host a number of different topics and it has come to serve as a hub, with multiple functions, such as posting news from media outlets and asking for support or additional work in order to make news publishable on Macao's social media channels. Secondly, together with the online platform, the CML constitutes a vibrant space of 
discussion concerning the assemblies and their agenda and for sharing information that is relevant to the life of Macao.

The data extracted from the CML amount to around 3,000 emails and span the period from June 2013 to June 2015. These data have been elaborated using Gephi and, together with Gephi's visualization capabilities, it allows us to understand to what extent women are implicated in Macao's communications. In fact, among the top ten contributors, we find only three men. More significantly, the first contributor, Giorgia, shows a degree of engagement that appears to be more than twice (weight $=1,337$ ) that of the second most active user (weight $=$ 668). Ethnographic insight gathered during the fieldwork allows us to understand that Giorgia is in fact the person who, from the beginning of Macao, has acted as the 'head' of Macao's communication. This information is represented graphically by the thickness of the edge that connects her to the central node, which represents the CML itself. Analyzing the data from the mailing list more closely, it is possible to see how greater activity does not necessarily correlate with the influence of a person's node. Influence is based here on betweenness centrality, a metric that indicates to what extent a person acts as an intermediary between two other people in the group. This metric is represented by the size and the darkness of a person: the darker and the bigger the node, the more influence a person has in the group (Image 11.1).

As shown in Graph 1, there is no linear correspondence between activity and influence. New subjects emerge, showing a substantially lower activity coupled with a much higher influence. In particular, two males (Paolo and Andrea) and a female (Federica) emerge as influencers. How is it possible to explain this discrepancy? Following the data, it shows that these three people have been

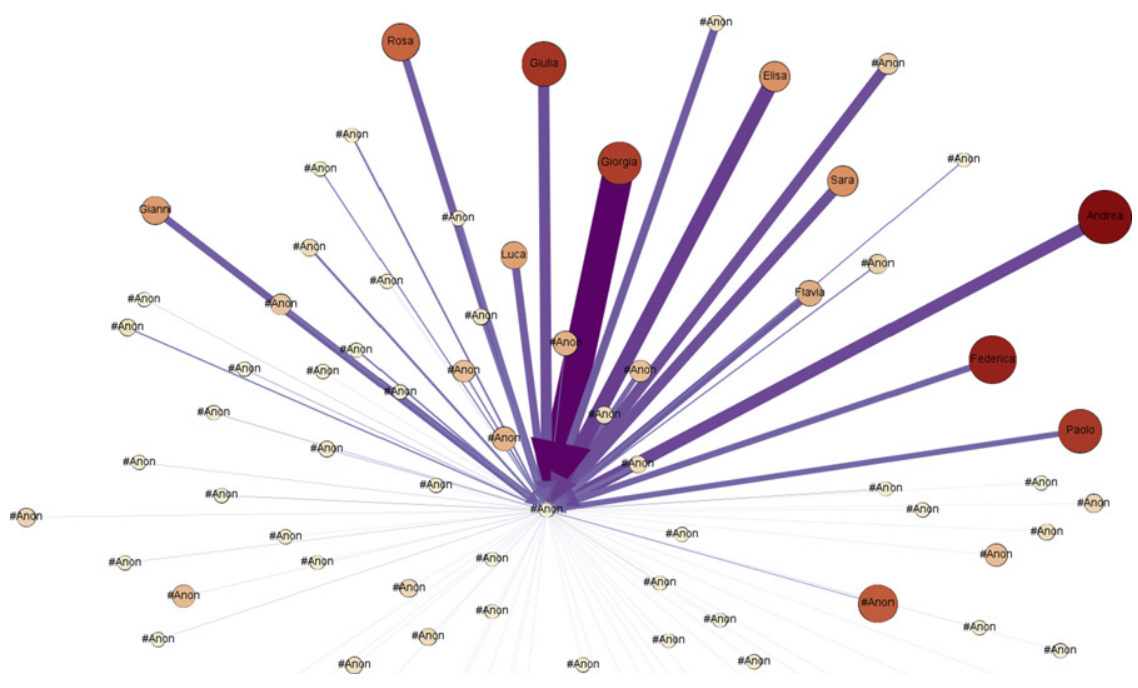

Image 11.1. Graph of CML Elaborated in Gephi 
engaging in email conversations with a wider number of participants and are therefore acting as connectors between different subgroups. Two of them were also part of the initial group that founded Macao, while Federica has been a very active member of the Macao theatre group and has therefore engaged in discussions with them, as well as linking their discussions to the main group. Therefore, I suggest that influence also reflects the social dynamics that take place in Macao's offline activities (Graph 11.1).

A tentative systematization of the differences that segment Macao can be drawn by using two axes, building an imaginary space within which to allocate Macao's constituency. The first axis represents artistic skills (AS), while the second axis accounts for communication skills (CS). The intersection of the two axes produces four ideal types of activist as regards the interlinkage between competences and communication: it produces four quadrants, representing different ideal-typical categories of Macao member. The first, showing a high degree of AS and a lower degree of CS, can be defined as a 'pure' artist: a person who is not particularly keen on manual and technical tasks, whose contribution is merely artistic (e.g., performing or organizing artistic events in Macao). The second category is the 'artistic communicator' and includes the people in Macao who not only have AS but are willing to transpose their AS into ideas that can be circulated in the digital space (e.g., setting up an 'artistically' inspired campaign to be diffused on Macao's Facebook page). The following category, the 'technical communicator', represents all those activists

\section{Macao Communication Mailing List Analysis}

\section{0}

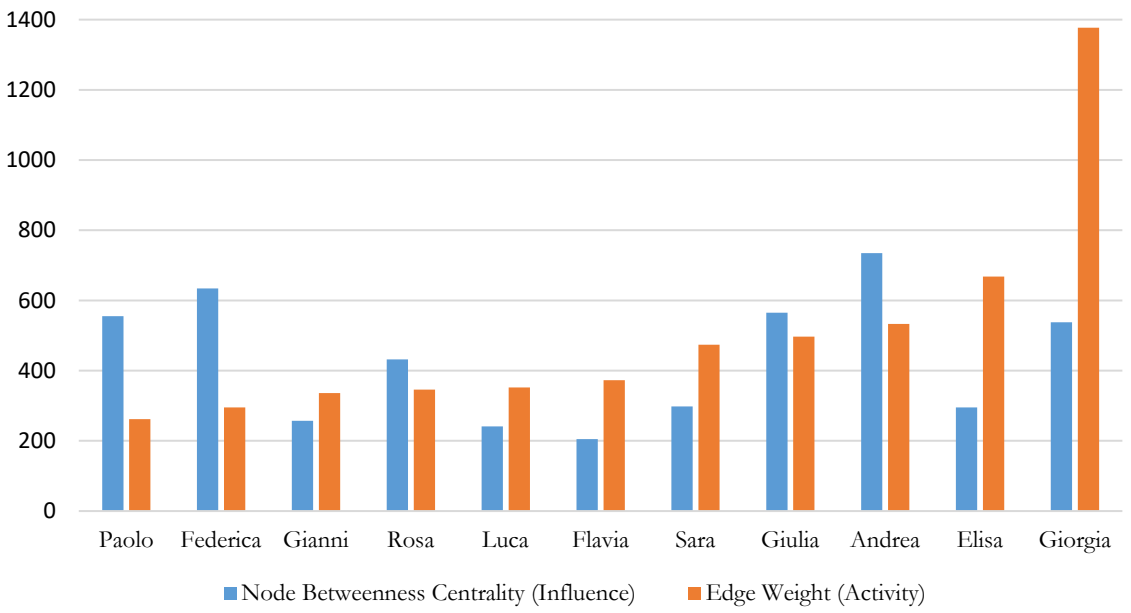

Graph 11.1. Analysis of CML for Betweenness Centrality and Edge Weight (Top 11 Users). 
who contribute to Macao's official communication but not necessarily by deploying highly creative processes. Activities in this area are closer to those of public relations and also include the sharing of artistic content through social media. Finally, the fourth category, which I have defined as 'technical activist', constitutes a residual category composed of subjects who show a low degree of both sets of skills and whose contribution to Macao lies in their manual/ technical work. This fourth category partially overlaps with the dwellers group but, as a highly stylized category, it also functions to produce difference from which the meaning of the other three categories derive. As in every classification, rigidity is a disadvantage when seeking analytical clarity. In fact, the same actor at different points in time can play a variety of these categories/ roles: a choreographer can act as a pure artist when s/he invents a performance to be staged in the urban space. S/he can become an artistic communicator by setting up a creative campaign based on that performance. S/he might be a pure technical communicator when s/he tags people online in order to secure higher visibility for the creative campaign, and, finally, s/he can be a purely manual activist when s/he repairs the floor of the room in which the choreography has been rehearsed. In particular, the activist I have described, capable of embodying the four different roles, actually represents a normative ideal that has been explicitly criticized within Macao. In the life of Macao, the ideal activist is someone who is dedicating resources and time to individual and collective projects created within the movement and, most importantly, is capable of responding to the four ideal audiences who scrutinize their work from every corner. This means that the ideal Macao activist must respond to a certain idea of engaged political art, show a high effectiveness and originality in his/her digital engagement and conform to a hard-working stereotype when it comes to sharing content or performing manual work for Macao. More specifically, the activist must not just respond to these normative requirements or ideal-typical audiences but they must also appear worthy of their cobelonging, in the eyes of the different concrete subgroups that populate Macao. Actually, very few people in any organization can perform multiple roles at the highest standard in terms of quality and/or commitment. In particular, what appears relevant in terms of conflicts within Macao is that if some of the knowledge workers tend to have - at least - the basic resources to perform clerical or manual tasks, the contrary is rarely the case. This helps us to connect the cleavage between the knowledge and material workers with the issue of leadership. In other words, given the higher accessibility of competences required to perform manual skills compared to the soft skills, the knowledge worker is more likely to get closer to the normative ideal that is prevalent in Macao. The picture is more complex because, as I have experienced in my ethnographic research, this does not simply result in sheer domination. In fact, it is thanks to the peculiar organizational model created and incessantly reinvented by Macao that effective counter powers are possible (Image 11.2). 


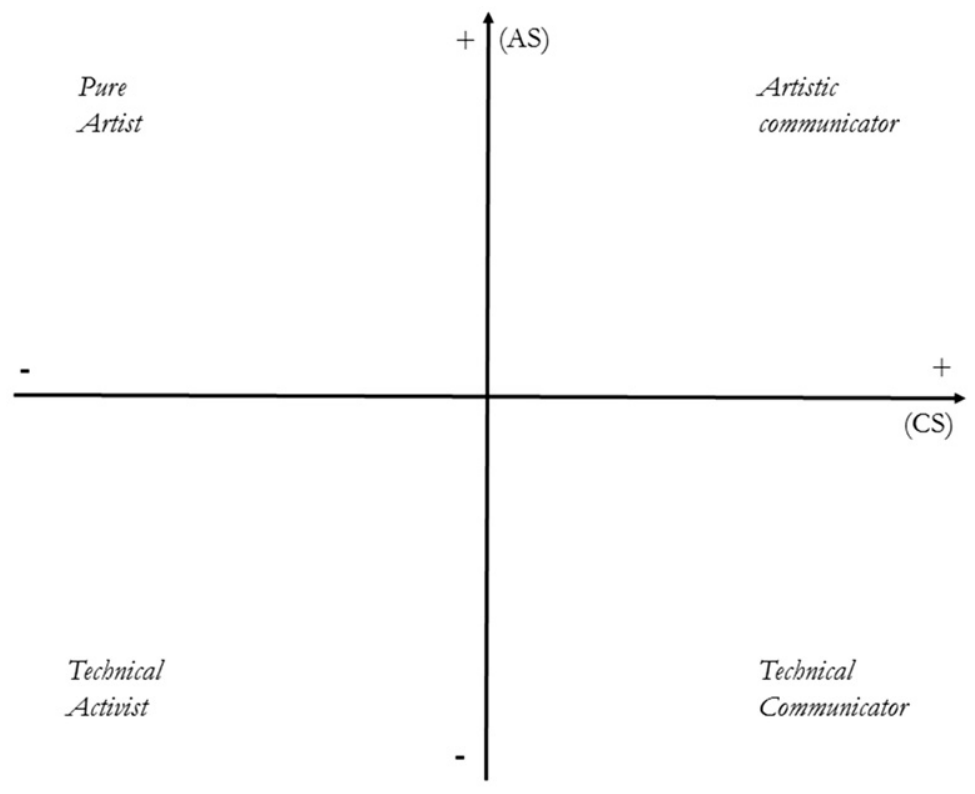

Image 11.2. Macao Constituency Ideal Types.

\section{Understanding Cooperation within Macao}

In order to highlight the specificity of Macao's organization, one must understand how cooperative practices within it can be driven by opposite drives; they can be either planned or spontaneous; they can be coordinated exclusively face-to-face and through personal social media or can be highly participative and mediated publicly in the intranet platform and in the assembly. These oppositions derive from a thorough analysis of two processes of collaborative making which took place in Macao during 2013 that I witnessed as a researcher: rebuilding the rooftop and organizing a media-wide campaign to address urban governance and policy (Image 11.3).

These examples are only two among the numerous activities and events that take place in Macao all the time. During 2013 alone, 270 events were organized, including music concerts, public seminars and talks, book fairs, exhibitions and artistic residencies. All of them see involved all or some of Macao activists in the organization, communication and realization of such events. On the one hand, this has led Macao activists to criticize the excessive 'usage' of events as a primary source of economic sustainability; on the other hand, it is what makes Macao a unique and necessary space for culture in Milan. The event then shows itself in its ambiguity, often criticized for its resemblance with the event economy that permeates the city; it represents at the same time a shared grammar by the citizenry Milanese through which they communicate and expose audiences to the unexpected. 


\begin{tabular}{|c|c|}
\hline Rebuliding the rooftop & «Non è mica luna» campaign \\
\hline Slow work rate & Dynamic and compulsive work rate \\
\hline Social division of labour & Inclusion of everyone \\
\hline Planned Activity & Evenful Activity \\
\hline Face-to face coordination and personal & Highly participative and mediated by the \\
\hline social media & common platform and the assembly \\
\hline Drive: material need sustained by a & Drive: desire sustained by small groups \\
\hline consensual agreement in the assembly & who try to contaminate others \\
\hline Inward orientation (taking care of their & Outward orientation (taking care of the \\
\hline "home”) & city) \\
\hline
\end{tabular}

Image 11.3. Comparison of Different Cooperative Practices.

How should we account for the coexistence of such different relational modes? In this attempt, I will start by briefly tracing a genealogy of cooperation in Macao. In the first instance, one major element pushing the Macao activists to act in such a particularly cooperative way is a critique of the existing relations in the creative industries in which many of the Macao activists live and work. Nevertheless, such a critique does not result in a paralyzing effect, as happened with the previous wave of mobilization on precarity (Mattoni, 2012). A different contribution comes from the actors' artistic backgrounds. As we know from Howard Becker (1984) and Bourdieu (1996), art is intrinsically a collective and social activity and seldom is the result of an isolated genius. However, what made possible the complex and collective work, that is, Macao, was the experience of Torre Galfa (see paragraph 1). The solidarity sparked in those early days is still, according to Macao activists, the main source of trust and mutual cooperation. This point is close to the argument put forth by Judith Butler in her essay 'Bodies in Alliance' about Tahrir Square (Butler, 2011) and is also deeply connected with the substantial import of feminist theory within Macao - in particular, in the 'politics of difference', a movement of subtraction and creation at the same time, based on the work of the feminist movements of the 1970s on relations (cf. Lonzi, 1978). The strong presence of women in the construction of Macao has moulded the movement's forms of action, giving essential importance to the quality of exchange rather than the goal, thus affirming the crisis in the whole business management ideology. This ideology is widespread in many projects of selfentrepreneurship in the creative industries (Bandinelli \& Arvidsson, 2013) with which Macao has established a nondogmatic dialogue, unlike its predecessors such as the social centres that have been active in Milan since the early 1980s. 


\section{Conclusions}

The first finding is related to what I define as a nonexclusive dialectic between the individual and the collective, which places Macao's relational pattern beyond the two main available frames of collective and connective action.

Through the results of the enquiry presented in this chapter, we can see how individual desires and needs are welcomed and find their expression in a dynamic interaction which does not always entail the approval of the assembly (Mode 11.6), similarly to what happens with the tasks carried out by the working groups. Furthermore, such desires arise both from people who are already active in Macao and from people who are entering Macao for the first time (Mode 11.1, 11.2, 11.3, 11.4).

The coordination in Macao does not take place in the way that it does within institutions such as unions. Coordination in Macao is a mobile, open and conflicting network in which the different types of associations (the working groups, assemblies, alliances, friendships, etc.) constitute spaces for the discussion, and the production, of skills, behaviours and expressions in constant transformation. How, then has this model been imagined and implemented? Three main elements come together in the explanation. As I have highlighted in the genealogy of cooperation in Macao, previous experiences and orientations inspired the model in the first place. Secondly, the ongoing experimentations brought about by Macao in its activity constantly generated new crossings by other subjects and ideas (Mode 11.5). Finally, these different models of organizing relations are able to coexist in the same space because of a desired instability, which - paradoxically - constitutes a 'sound floor' on which activities are based. Instability is a feature that characterizes many organizations in the present day, both within and outside the realm of SMs, and it does not represent an unintended negative outcome of systemic dysfunctions. As Boltanski and Chiapello (2005) have highlighted, capitalism itself has drawn ideas from countercultures and implemented them in new management theories. In Macao's case, however, there has been a step forward. Insofar as there is a shared awareness of already being subsumed into the neoliberal capitalist mode of production, the reflexive desire to have an unstable organization represents the outcome of a process of political subjectification in which the refusal of

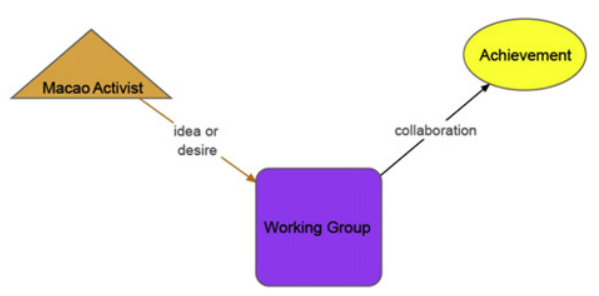

Mode 11.1. Macao Activist through Working Group. 


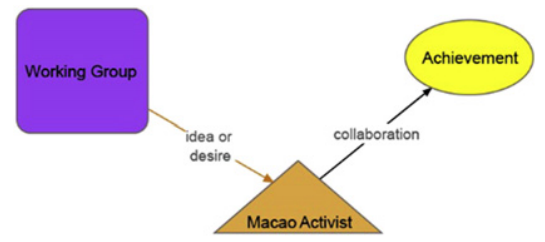

Mode 11.2. Working Group Activates Individual Macao Activist.

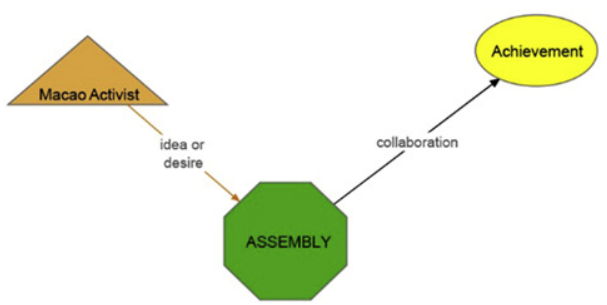

Mode 11.3. Macao Activist through Assembly.

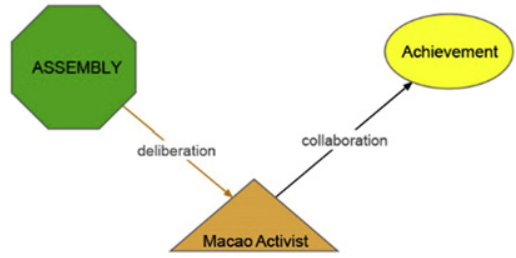

Mode 11.4. Assembly Activates Individual Macao Activist.

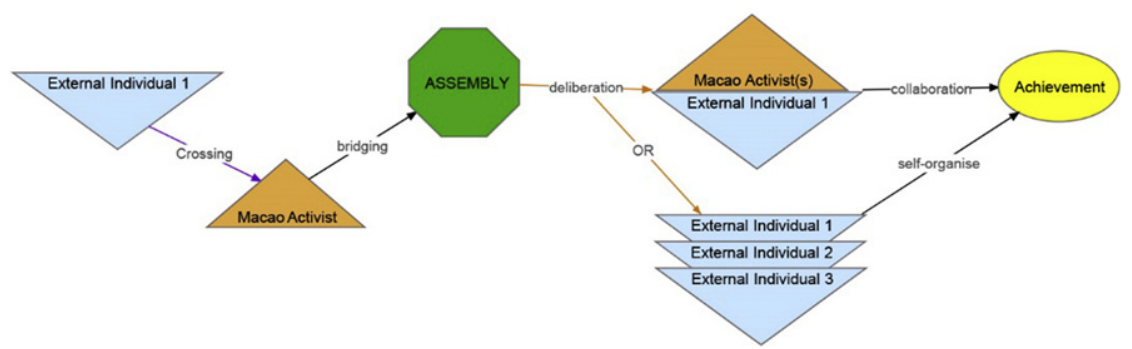

Mode 11.5. External Individual Crosses Macao. 


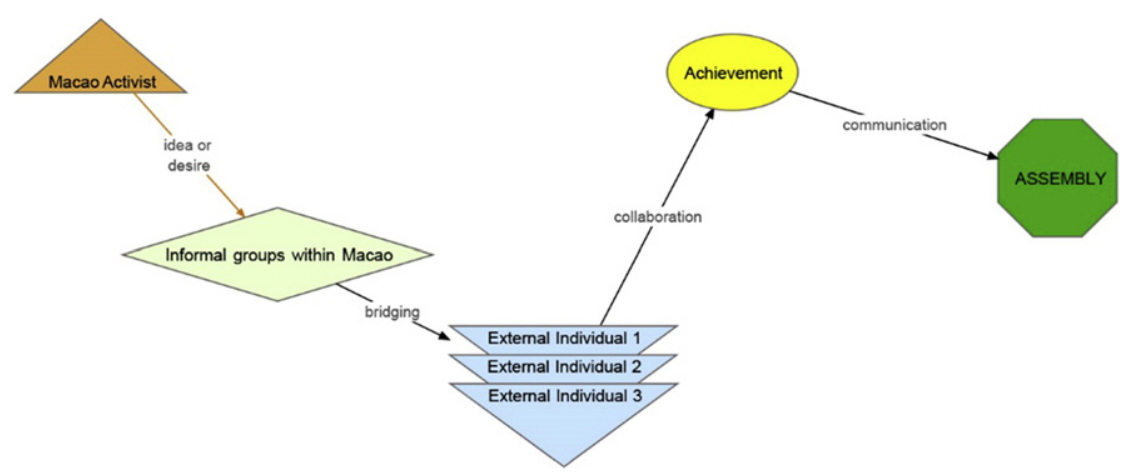

Mode 11.6. Informal Contamination without Deliberation Including Insiders and Outsiders.

work (Lazzarato, 2014) appears as a key component. Rather than being a hegemonic - and thus naturalized and prereflexive - frame for Macao, the desire to be unstable constitutes a safeguard against self-exploitation.

The second finding deals with the organization of participation along the opposed and coexisting notions of horizontality and hierarchy. In Macao, there is a constantly shifting equilibrium of radical inclusion and leadership. On the one hand, radical inclusion is granted by the 'crossings' by other subjects and groups that Macao, as a process and as a space, empirically supports by having, for instance, a weekly assembly that is fully open. Regardless of their status individual, group, acting inside or outside Macao - everyone in these assemblies is welcome and is granted a space in which it is possible to propose ideas and collaborations. However, this does not necessarily imply agreeing dogmatically with horizontality. In fact, leadership, and not leaders, represents a concrete reality in the activities of Macao. As Simon Western (2014) has suggested, in many contemporary movements, leadership is not just de facto already in place, it is an unavoidable and beneficial feature of every human grouping, as anarchists in the first place have also acknowledged. In Western's account, it was exactly an unwillingness to recognize leadership in movements like Occupy and Indignados that caused growing dissatisfaction among activists and led to their dissolution. What is different in Macao then? As I have stressed in the first finding, desire is actively pursued and given free rein so that it can permeate assemblies or, in other cases, simply ignore them and bypass them. Furthermore, there is a strong recognition of individual qualities and differences. Different forms of leadership are simultaneously copresent as they are disseminated in the social body of Macao, leading projects that might involve highly diverse skills and interests (e.g., organizing a theatre festival vs. a seminar on free software).

The fourth and main finding relates to the overall organizational model of Macao. In a previous article (Cossu \& Murru, 2015), I have highlighted how the 
event represented a fundamental logic that guided the Macao activists' political action in the public sphere. I have also stressed how it contained a deep ambivalence, especially to the extent that the threshold separating a staged event from a disruptive event, a media event from a more authentic event that is bodily and emotionally perceived, is very thin. This ambivalence is still present and the event seems to play a role in the mechanics that govern the organization of Macao. From this point of view, the event is the minimal unit which compels activists to cooperate within a 'just-in-time' regime of production that appears all too close to the regimes experienced by less politicized cultural workers. Within a framework, events offer a manageability that leaves room for a critique of work beyond selfexploitation, as highlighted by the slow work rate that defines many of Macao's activities. Furthermore, what must be considered is the fact that the current Italian political arena is not capable of mediating the needs originating from art and cultural workers, as traditional collective actors appear unfit and unwilling to represent them, thus leaving a gap to be filled. Such a gap has been occupied by hybrid organizations that bear the heritage of SMs, artistic avant-gardes and workers' movements, like Macao and many others around Italy and Europe. If, traditionally, action was structured around organizations producing events (e.g., trade unions calling for a general strike or a rally), if the main economic system is centred around the event economy, if access to power through institutionalization (e.g., becoming a union) or cooptation is no longer either feasible or desirable, if the only means available to change capitalism is from within (since there is no outside), what happens to the concept of organization for this type of hybrid movement? In this context, as highlighted by the experience of Macao, the appropriation of a capitalist logic for political purposes requires us to rethink organization as we are used to conceive of it (that is, an organization that produces events) and rather to think of it as a linking of events. In other words, as the event becomes a key organizational device, the new organization is no longer a unity that produces events in order to persist with its structures and roles but becomes itself a series of events that loosely interweave the organization of action and production.

\section{References}

d'Ovidio, M., \& Cossu, A. (2016). Culture is reclaiming the creative city: The case of Macao in Milan, Italy. City, Culture and Society, 8, 7-12. doi:10.1016/ j.ccs.2016.04.001

Arvidsson, A., Caliandro, A., Airoldi, M., \& Barina, S. (2015). Crowds and value, Italian directioners on Twitter. Information, Communication and Society, 19(7), 921-939.

Arvidsson, A., \& Peitersen, N. (2013). The ethical economy: Rebuilding value after crisis. New York, NY: Columbia University Press.

Bandinelli, C., \& Arvidsson, A. (2013). Brand yourself a changemaker!. Journal of Macromarketing, 33(1), 67-71.

Barker, C. (2001). Robert Michels and 'the cruel game'. In C. Barker, A. Johnson, \& M. Lavalette (Eds.), Leadership and social movements. Manchester: Manchester University Press. 
Barker, C., Cox, L., Krinsky, J., \& Gunvald, A. (Eds.). (2013). Marxism and social movements. Leiden and Boston, MA: Brill.

Becker, H. S. (1984). Art worlds. Oakland, CA: University of California Press.

Bennett, L., \& Segerberg, A. (2013). The logic of connective action. Digital media and the personalization of contentious politics. Cambridge: Cambridge University Press.

Boltanski, L., \& Chiapello, E. (2005). The new spirit of capitalism. London: Verso.

Bourdieu, P. (1996). The rules of art: Genesis and structure of the literary field. Stanford, CA: Stanford University Press.

Butler, J. (2011). Bodies in alliance and the politics of the street. Transveral, 9, 1-29. Retrieved from http://www.eipcp.net/transversal/1011/butler/en

Campbell, J. L. (2005). Where do we stand? Common mechanisms in organizations and social movements research. In G. F. Davis, D. McAdam, W. R. Scott, \& M. N. Zald (Eds.), Social movements and organization theory. Cambridge: Cambridge University Press.

Castells, M. (2012). Networks of outrage and hope: Social movements in the internet age. Cambridge, MA: Polity.

Cirillo, L. (2014). Lotta di classe sul palcoscenico: I teatri occupati si raccontano. Rome: Alegre.

Clemens, E. S. (2005). Two kinds of stuff: The current encounter of social movements and organizations. In G. F. Davis, D. McAdam, W. R. Scott, \& M. N. Zald (Eds.), Social movements and organization theory (pp. 351-365). Cambridge: Cambridge University Press.

Cossu, A., \& Murru, M. F. (2015). Macao prima e oltre i social media: la creazione dell'inatteso come logica di mobilitazione [Macao before and beyond social media: the creation of the unexpected as a mobilisation logic.]. Studi Culturali, 3, 353-372. doi: $10.1405 / 81912$

Davis, G. F., McAdam, D., Scott, W. R., \& Zald, M. N. (Eds.). (2005). Social movements and organization theory. Cambridge: Cambridge University Press.

Davis, G., \& Zald, M. N. (2005). Social change, social theory, and the convergence of movements and organizations. In G. F. Davis, D. McAdam, W. R. Scott, \& M. N. Zald (Eds.), Social movements and organization theory. Cambridge: Cambridge University Press.

Freeman, J. (1972). The tyranny of structurelessness. Second Wave, 2(1), 20-33.

Ganz, M. (2000). Resources and resourcefulness: Strategic capacity in the unionization of California agriculture, 1959-1966. American Journal of Sociology, 105, $1003-1062$.

Gerbaudo, P. (2015). Rousing the Facebook crowd: Social media campaigning, digital enthusiasm and the online plebeian public sphere in the 2011 protest wave. Working paper presented at the University of Milan, 31 March 2015. University of Milan, Milan.

Giorgi, A. (2014). Le mobilitazioni dei lavoratori della cultura, dell'arte e dello spettacolo. In L. Alteri \& L. Raffini (Eds.), La nuova politica: Mobilitazioni, movimenti e conflitti in Italia. Naples: Edises.

Gonzalez-Bailon, S., \& Wang, N. (2013). Networked discontent: The anatomy of protest campaigns in social media. Social Networks, 44, 95-104. Retrieved from http://ssrn.com/abstract=2268165 or http://dx.doi.org/10.2139/ssrn.2268165

Isola Art Centre. (2013). Fight-Specific Isola. Arte, Architettura, Attivismo e il Futuro della Città. Berlin: Archive Books. 
Lazzarato, M. (2014). Marcel Duchamp e il Rifiuto del Lavoro. Milan: Edizioni Temporale.

Leach, D. (2013). Culture and the structure of Tyrannylessness. The Sociological Quarterly, 54, 159-228.

Lonzi, C. (1978). Sputiamo su Hegel. La donna clitoridea e la donna vaginale e altri scritti. Milan: Scritti di Rivolta Femminile.

Mattoni, A. (2012). Media practices and protest politics. How precarious workers mobilise. Farnham: Ashgate.

McAdam, D., \& Scott, R. W. (2005). Organizations and movements. In G. F. Davis, D. McAdam, W. R. Scott, \& M. N. Zald (Eds.), Social movements and organization theory. Cambridge: Cambridge University Press.

Mirzoeff, N. (Ed.). (2013). Militant research handbook. New York, NY: NYU Digital Publication. Retrieved from http://steinhardt.nyu.edu/scmsAdmin/media/users/ dhp238/Faculty_Projects/MRH_Web_SinglePage.pdf. Accessed on January 14, 2017.

Moore, A. W. (2015). Occupation culture. Art \& squatting in the city from below. New York, NY: Minor Compositions.

Nunes, R. (2014). Organization of the organizationless: Collective action after networks. London: Mute Books \& Post-Media Lab.

Pruijt, H. (2013). The logic of urban squatting. International Journal of Urban and Regional Research, 37(1), 19-45.

Roberts, A. (2012). Why the occupy movement failed. Public Administration Review, 72(5), 754-762.

Rogers, R. (2013). Digital methods. Cambridge, MA: MIT Press.

Sholette, G. (2011). Dark matter: Art and politics in the age of enterprise culture. London: Pluto Press.

Swann, T., \& Stoborod, K. (2014). Did you hear about the anarchist manager? In Ephemera Journal, 14(4), 591-609.

Valli, C. (2015). When cultural workers become an urban social movement: Political subjectification and alternative cultural production in the Macao movement, Milan. Environment and Planning A, 47, 643-659.

Western, S. (2014). Autonomist leadership in leaderless movements: Anarchists leading the way. Ephemera Journal, 14(4), 673-698. 